\title{
South African Spinal Cord Association
}

The First South African Spinal Cord Congress was held on 30-31 October 1993 at Maccauvlei, Vereeniging. Guest speakers were Dr Paul Dollfus, the President of IMSOP, and Dr David Burke from Australia.

Mrs Christa Meyer, an occupational therapist well known in the field, presented the Ailie Key Memorial Lecture. Her topic was 'Rehabilitation of the spinal cord injured in the future South Africa-where to?'

It is hoped that this lecture will become a feature of all future congresses. The congress was attended by 150 delegates from all disciplines. Much useful information was obtained particularly from therapists and social workers working with spinal cord injury in the field who demonstrated the difficulties of reintegration in the Third
World.

The final session was devoted to the formation of the South African Spinal Cord Association. This association will be multidisciplinary and its council will consist of representatives of all disciplines engaged in the treatment and rehabilitation of those with afflictions of the spinal cord. The executive committee consists of a president (medical) assisted by two vice presidents (one medical, one paramedical), a secretary and a treasurer.

It is intended to hold a congress biennially and also to apply for affiliation to IMSOP. Anyone requiring further information should apply to: The Secretary, South African Spinal Cord Association, Rand Mutual Hospital, PO Box 62171, 2107 Marshalltown, South Africa. 